\title{
Understanding the Genetics of Age-Related Macular Degeneration: Some Insights into the Disease Pathogenesis
}

\author{
Inderjeet Kaur ${ }^{1}$, Yashoda Ghanekar² and Subhabrata Chakrabarti* ${ }^{1 *}$ \\ ${ }^{1}$ Kallam Anji Reddy, Molecular Genetics Laboratory, ${ }^{2}$ Sudhakar and Sreekanth Ravi Stem Cell \\ Biology Laboratory, L.V. Prasad Eye Institute, Hyderabad, Andhra Pradesh, India
}

KEYWORDS AMD; genes; SNP; genotype; association; $C F H$

\begin{abstract}
Age-related macular degeneration (AMD) is a late-onset complex disorder with multifactorial etiologies. Both genetic and environmental factors play a role in the disease pathogenesis. AMD is the third leading cause of blindness in the elderly. Familial aggregation, segregation studies and linkage analysis have provided both qualitative and quantitative evidence on the genetic basis in AMD. Several candidate loci have been earlier mapped in AMD but variants in genes viz. APOE, ABCA4, FBLN6 and EFEMP1 harboring these loci have accounted for only a small proportion of cases. Recent screening of two major loci has led to the identification of the Complement Factor $\mathrm{H}$ $(C F H)$ on 1q32 and LOC387715 and HTRA1 on the 10q26 gene cluster. Single nucleotide polymorphisms (SNPs) in CFH (Y402H), LOC387715 (A69S) and a promoter variant in HTRA1 have been associated with AMD in large casecontrol cohorts. These SNPs exhibited large effect sizes and high disease odds for the risk genotypes across different populations. Interestingly, these associations have been widely replicated across multiple ethnic groups worldwide indicating their potential role in the disease pathogenesis. In this review, we would outline the genetics of AMD with special emphasis on $\mathrm{CFH}$ followed by other genetic variants based on studies done by our group and colleagues worldwide. We would also provide a brief overview on the possible molecular mechanisms leading to AMD.
\end{abstract}

\section{INTRODUCTION}

Visual impairment leading to blindness is a major impediment towards growth and development in populations worldwide. The burden of blindness is a global challenge that needs to be tackled on a war footing. Recent estimates of the World Health Organization (WHO) indicate that around 45 million people are blind and 135 million are visually impaired worldwide and $90 \%$ of these people live in the developing countries. Among the blinding conditions, cataract accounts for $60 \%$ of global blindness, followed by glaucoma (12.3\%). Age-related macular degeneration (AMD) is the third leading cause of blindness and accounts for $8.7 \%$ of the world population (WHO Fact sheet no. 282). Although AMD is more common among the elderly in the developed countries, it is becoming a cause of concern in the developing countries as well with senescence, fast demographic changes and life styles.

\section{The Problem}

AMD causes progressive impairment of

*Corresponding Author: Dr. Subhabrata Chakrabarti Brien Holden Eye Research Centre, L.V. Prasad Eye Institute, Road No. 2, Banjara Hills, Hyderabad 500 034, Andhra Pradesh, India

Telephone: 91-40-30612524, Fax: 91-40-23548271

E-mail: subho@1vpei.org,subho_c@yahoo.com central vision and is a leading cause of irreversible vision loss worldwide. The overall prevalence of late stage AMD varies from $1.4 \%$ to $1.7 \%$ across different epidemiological cohorts (Klein et al. 1992, 1994; Mitchell et al. 1995) and increases significantly with age. It is estimated that by the year 2020, around 8 million people will have vision loss due to retinal complications including AMD (Bressler 2002). As it leads to irreversible blindness, managing AMD is a global public health challenge.

In India, the epidemiological report of the Andhra Pradesh Eye Disease Study (APEDS) indicated that $1.84 \%$ of the population is blind with a visual acuity of $<6 / 60$ or central visual field loss $<20^{\circ}$ in better eye (Dandona et al. 2001). Retinal diseases are an important cause of vision loss in India with an estimated prevalence of 10.3\% (Balasubramanian 2002; Nirmalan et al. 2004). The prevalence of AMD in India ranges from 1.84-2.7\% (Nirmalan et al. 2004), similar to the global prevalence.

\section{RISK FACTORS IN AMD}

Epidemiological surveys conducted on large case-controls cohorts have identified several demographic and environmental risk factors in AMD. The Age-related Eye Disease Study (AREDS) conducted on large Caucasian cohorts indicated 
gender, age and smoking as important risk factors in the development of AMD (AREDS 2000, 2005). This was later replicated in many studies done on other ethnic groups (Krishnaiah et al. 2005). These risk factors are briefly described as follows:

1. Gender: The incidences of early and late AMD are 2-7 times more in females than males, > 75 years of age, respectively (Klaver et al. 1998a). The high risk in females may be due to the loss of a protective effect of estrogens in postmenopausal women.

2. Race: It has been demonstrated that the incidence of AMD is relatively lower in Blacks than Whites (Klein et al. 1992). The reported incidence in Indian population is around 1.2\%.

3. Cigarette Smoking: Smoking has been postulated to cause AMD by depression of serum antioxidant levels and alteration of choroidal blood flow and detoxification of the retinal pigment epithelium (RPE). It has been hypothesized that decrease in luteal pigments in human retina due to cigarette smoking may cause light and oxidative damage to the macula, thereby leading to an increased risk of developing AMD. Cross sectional data from the population based surveys have also shown a significant relationship between smoking status and risk of late AMD (Klein et al. 1993; Tomany et al. 2004a)

4. Alcohol Consumption: Alcohol intake causes tissue damage by increasing the oxidative stress or affecting mechanisms that protect against oxidative damage to retina. The inconsistent findings among various studies, however, suggest that consumption of alcoholic beverages is not likely to be an important risk factor for the incidence of AMD at this point of time (The Eye Disease CaseControl Study Group 1992).

5. UV Radiation: Data from animal studies and case reports have suggested that exposure to intense bright sunlight or ultraviolet radiation may cause changes in the RPE similar to changes seen in AMD (Tomany et al. 2004a).

6. Diet: Diet has been related to several chronic conditions including cancer, coronary heart disease, and cataract. It may also have an important role in preventing and slowing the development of AMD (Seddon et al. 1994).

\section{Genetics of AMD}

The genetic basis of AMD was relatively ignored for many years as other causes for the disease were explored. Genetic epidemiological studies have revealed that genetic differences between populations might play an important role in explaining the prevalence among diverse ethnic groups. Higher concordance among the monozygotic twins, familial aggregation and segregation analyses have suggested a strong genetic basis for the disease (Seddon et al. 1997, 2005; Klaver et al. 1998a). Several genome-wide linkage studies have identified a number of putative loci for AMD but only a few of these regions have been replicated independently. The susceptible loci have been mapped to chromosomes 1q, 9q, $10 \mathrm{q} 22 \mathrm{q}$ and $16 \mathrm{q}$, but no causative mutation has been reported in the genes located in these regions (Weeks et al. 2000, 2004; Seddon et al. 2003; Majewski et al. 2003; Schmidt et al. 2004). The first locus for AMD at 1q25-31 was mapped by Klein et al.(1998) in a large family, however, the mutation Q5345R in the Fibulin gene harboring this locus could not sufficiently prove its contributions to AMD pathogenesis. Several Candidate genes responsible for macular and retinal dystrophies (ELOVL4 and ABCA4: Stargardt disease; TIMP3: Sorsby fundus dystrophy; and Peripherin: retinal degeneration) that share common features with AMD were extensively screened for their involvement in AMD (Ayyagari et al. 2001; Allikmets et al. 1997, 1999; Akimoto et al. 2001; De La Paz et al. 1997; Shastry et al. 1999; Stone et al. 1999; Haines et al. 2006). But the variation in these genes could account for only a small subset of cases.

Recently, some major candidate genes have been identified in large case-control cohorts that explain a substantial proportion of AMD:

a) Complement Factor $\mathrm{H}(\mathrm{CFH})$ Gene: The polymorphism $\mathrm{Y} 402 \mathrm{H}$ in the Complement Factor $\mathrm{H}(\mathrm{CFH})$ gene has been shown to be significantly associated with AMD susceptibility. $\mathrm{CFH}$ on $1 \mathrm{q} 32$ is an important regulator of complement system of innate immunity. AT C substitution at 1277 nucleotide in exon 9 of $C F H$ resulting in a change of tyrosine to histidine $(\mathrm{Y} 402 \mathrm{H})$ increases an individual's risk of having AMD by several folds. The odds ratio for AMD reported by these studies ranged between 2.4- 4.6 for the risk allele " $C$ " and between 3.3-11.5 for those with the risk genotype "CC". The association of the Y402H SNP in AMD across different studies worldwide is shown in Table 1. However, the exact role of $\mathrm{Y} 402 \mathrm{H}$ to different phenotypes of AMD has not 
Table 1: Distributions of odds ratios for the homozygous and heterozygous "risk" genotypes along with the significance of the "risk" allele for the Y402H SNP $(\mathrm{CFH})$ across different studies

\begin{tabular}{llcrrr}
\hline $\begin{array}{l}\text { Different studies on the } \\
\text { Y402H SNP [n=AMD cases] }\end{array}$ & Population & $\begin{array}{c}\text { Significance }(p \text { value }) \\
\text { of the risk allele* }\end{array}$ & OR $_{\text {Hom }}(95 \% C I) \dagger$ & $O_{\text {Het }}(95 \% C I) \neq$ \\
\hline Edwards et al. 2005[n=395] & American & $4.95 \times 10^{-10}$ & 4.54 & $(2.70,7.65)$ & $2.14(1.43,3.18)$ \\
Haines et al. 2005[n=94] & American & 0.00006 & 3.33 & $(1.79,6.20)$ & $2.45(1.41,4.25)$ \\
Hageman et al. 2005[n=952] & American & $2.1 \times 10^{-12}$ & 5.44 & $(3.82,7.76)$ & $2.53(1.93,3.31)$ \\
Zareparsi et al. 2005a[n=616] & American & $<1 \times 10^{-24}$ & 5.52 & $(3.54,8.59)$ & $4.36(3.13,6.08)$ \\
Seddon et al. 2007[n=1466] & American & $<0.001$ & 2.60 & $(1.70,3.90)$ & $1.60(1.00,2.40)$ \\
Sepp et al. 2006[n=443] & British & $<0.0005$ & $6.30(3.80,10.40)$ & $3.10(2.00,4.60)$ \\
Magnusson et al. 2006[n=1330] & Icelandic & $2.1 \times 10^{-21}$ & 4.13 & $(3.28,5.20)$ & $1.87(1.55,2.25)$ \\
Seitsonen et al. 2006[n=335] & Finnish & $1.32 \times 10^{-11}$ & $9.79(4.76,20.10)$ & $2.51(1.46,4.31)$ \\
Rivera et al. 2005[n=1166] & German & $6.7 \times 10^{-29}$ & 6.72 & $(5.14,8.79)$ & $1.99(1.61,2.46)$ \\
Souied et al. 2005[n=141] & French & $<0.0001$ & $6.93(3.11,15.46)$ & $3.00(1.60,5.62)$ \\
Simonelli et al. 2006[n=104] & Italian & $<0.001$ & 3.90 & $(1.90,8.20)$ & $1.40(0.70,2.60)$ \\
Kaur et al. 2006[n=100] & Indian & $1.19 \times 10^{-7}$ & $11.52(5.05,26.28)$ & $1.51(0.82,2.80)$ \\
Baird et al. 2006[n=236] & Australian & $<0.001$ & $9.26(4.52,18.98)$ & $1.86(1.10,3.67)$ \\
\hline
\end{tabular}

* Significance of the risk allele ("C"); †Odds ratios for genotypes with homozygous risk alleles (CC); $\ddagger$ Odds ratios for the genotypes with one copy of the risk allele (TC)

been clearly shown in any of these studies. This could be due to more number of neovascular AMD or lack of sufficient clinical information. Magnusson et al. (2006) further investigated the association of $\mathrm{CFH}$ and AMD based on genotype-phenotype correlations and observed that the $\mathrm{Y} 402 \mathrm{H}$ allele confers a significant risk to both late stages (neovascular AMD, Geographic Atrophy) and early stages of AMD (soft drusens) in US and European AMD patients. It was also observed that the $\mathrm{Y} 402 \mathrm{H}$ variant contributes to increased risk of advanced AMD through its involvement on the development of soft drusens which are precursors of advanced AMD phenotypes. This SNP has been implicated in most AMD populations worldwide, except in the Japanese (Gotoh et al. 2006, Okamoto et al. 2006).

Hageman et al. (2005) analyzed haplotypes using eight intragenic SNPs in $\mathrm{CFH}$ and also the immuno-histochemical status of drusen and sections of cadaveric eye in AMD patients. Their analysis revealed a risk haplotype, which had almost two-folds higher frequency among the cases $(50 \%)$ than controls $(29 \%)$. Two protective haplotypes for AMD were also identified among the controls.

\section{Role of Complement Activation and Inflammation in the Pathogenesis of AMD}

$\mathrm{CFH}$ is an important regulator of complement system of innate immunity against microbial infection. This regulation of complement activity is achieved by the binding of $\mathrm{CFH}$ to $\mathrm{C} 3 \mathrm{~b}$ (generated by the cleavage of a chains of $\mathrm{C} 3$ ), thereby stopping the production of C5b-9 (the component of membrane attacking complex). Further details are provided in Figure 1. The $\mathrm{Y} 402 \mathrm{H}$ residue located within the binding sites for heparin and C-reactive protein. Altered binding of $\mathrm{CFH}$ to these proteins results in changes in $C F H$ 's ability to suppress the complement-related damage to the host cells (Clark et al. 2006; Johnson et al. 2006). These studies gave a strong evidence for the role of inflammation and dysfunction of complement pathways in the pathogenesis of AMD.

b) Factor $B$ and Complement Component 2: Recently, Gold et al. (2006), reported a strong association of variation in the Factor $\mathrm{B}(B F)$ and complement component $2(C 2)$ genes with AMD. $B F$ and $C 2$ genes are located in the major histocompatibility complex class III region (6p21). The L9H and R32Q variants in $B F$ and E318D and an intron 10 variant in $C 2$ were found to confer significantly reduced risk of AMD. When these haplotypes were analyzed together with $\mathrm{CFH}$ variants it was shown that variation in these two loci can predict clinical outcome in $74 \%$ of the affected individuals and $56 \%$ of the controls.

$B F$ and $C 2$ are expressed in the neural retina, RPE and choroids. Additionally the $B F$ protein was observed in ocular drusen and Bruch's membrane. Glutamine at position 32 of this protein has been shown to have reduced hemolytic activity as compared to wild type Arg32 (Lokki and Koskimies 1991). BF is an important activator of the alternative complement pathway and thus may result in AMD by abnormal BF activity.

c) Genes in the 10q26 Cluster: The second 


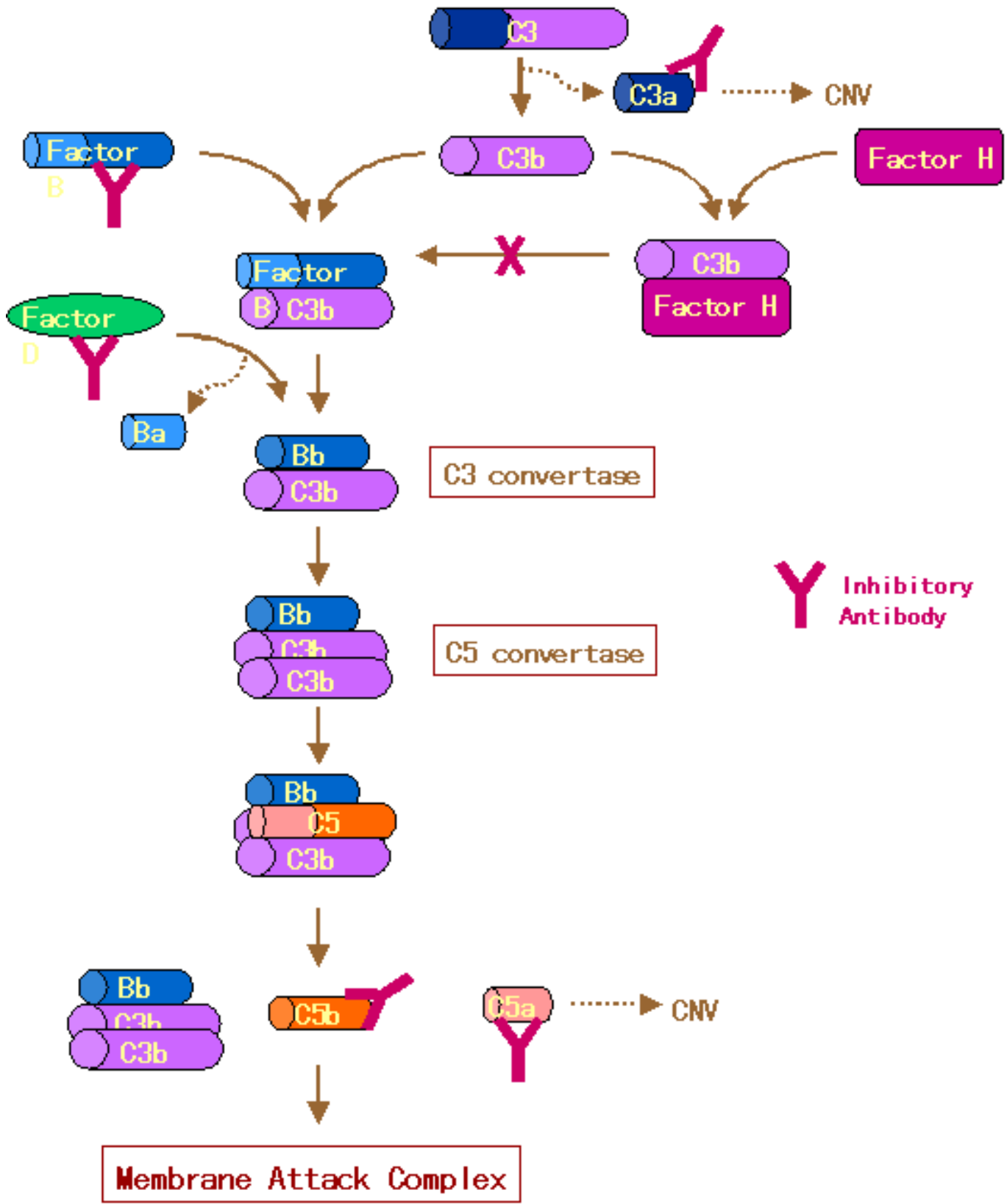

Fig. 1. Alternate Pathway of Complement Activation: The alternate pathway of complement activation is initiated by binding C3b to Factor B. Serum C3 slowly hydrolyses spontaneously into C3a and C3b. C3b binds Factor $\mathrm{B}$ which can now be cleaved by Factor D. Complex of $\mathrm{C} 3 \mathrm{bBb}$ thus formed then acts as $\mathrm{C} 3$ convertase and generates more C3b. The complex further binds another C3b molecule and acts as C5 convertase. The C5 convertase binds and cleaves $\mathrm{C} 5$ into $\mathrm{C} 5 \mathrm{a}$ and $\mathrm{C} 5 \mathrm{~b}$. C5b then initiates membrane attack complex. Complement factor $\mathrm{H}$ inhibits this sequence of events by binding to $\mathrm{C} 3 \mathrm{~b}$, thereby inhibiting its binding to Factor B. The pathway can also be inhibited by using antibodies that inhibit action of Factor D, Factor B or C5b. In drusen C3a and C5a generated during this pathway can stimulate choroidal neovascularization and inhibitory antibodies against these two components could be a therapeutic modality for AMD. 
AMD locus mapped on 10q26 harbored three important candidate genes PLEKHAI (OMIM 607772), hypothetical LOC387715 and HTRA Serine Peptidase 1 (HTRA1; OMIM 602194) (Jakobsdottir et al. 2005). Resequencing of this cluster revealed a significant association of the A69S SNP in LOC387715 gene in two large AMD cohorts of German origin (Rivera et al. 2005). These results were further replicated in Caucasian (Conley et al. 2006; Ross et al. 2007; Seddon et al. 2007), Japanese (Tanimoto et al. 2006) and Russian (Fisher et al. 2006) AMD patients. The risk of AMD was strongly modified in subjects harboring the A69S SNP along with a history of smoking (Schmidt et al. 2006).

Very recently, another SNP (rs11200638) located $512 \mathrm{bp}$ upstream of the transcription site of HTRA1 gene in the same 10q26 cluster, was implicated in three independent reports on Caucasian (Yang et al. 2006; Cameron et al. 2007), Chinese (DeWan et al. 2006) and Japanese (Yoshida et al. 2007) AMD subjects. This SNP was suggested to be in strong linkage disequilibrium (LD) with the LOC387715 variant. While, the function of both these variants are yet uncharacterized, two locus odds ratios have indicated significant risk conferred by the HTRA 1 variant in conjunction with the $C F H$ variant Y402H (Cameron et al. 2007).

d) $\boldsymbol{A P O E}$ : In the past few years, association of variants in genes involved in lipid metabolism such as Apolipoprotein E ( $A P O E$ ) have increased our understanding of the underlying mechanism of AMD development. Based on common pathogenic features including lipid deposition (drusen and plaque formation), thickening of connective tissue (Bruch's membrane and arterial inner lining) and elevated levels of CRP in serum, a common mechanism for the development of AMD and atherosclerotic cardiovascular diseases was proposed (Freidman 2000). However, it was noted that the effect of $A P O E$ alleles on AMD risk was contrastingly different than that of atherosclerosis and cardiovascular diseases Association of APOE in AMD has been reported by several groups (Klaver et al. 1998b; Schmidt et al. 2000, 2002; Baird et al. 2004; Zareparsi et al. 2004) showing a reduced risk of AMD with $A P O E-\varepsilon 2$ allele and higher risk with allele APOE$\varepsilon 4$. However, $A P O E$ polymorphisms have exhibited varied geographical and ethnic variations across AMD patients worldwide.

e) Toll like receptor 4 (TLR4): A recent study by Zareparsi et al. (2005) implicated the TLR4 gene (9q32-33) in AMD pathogenesis. Toll like receptors are involved in innate immunity and pathogen recognition (Cook et al. 2004), linked to regulation of cholesterol efflux and participates in phagocytosis of photoreceptor outer segments by the RPE (Kiechl et al. 2002; Castrillo et al. 2003; Kindzelskii et al. 2004; Blander et al. 2004). The D299G polymorphism in TLR4 was associated with a 2.65 folds increased risk of AMD, thereby suggesting that altered TLR 4 signaling by this variant may influence phagocytic function of RPE which in turn may contribute to RPE damage. It was also shown that TLR4-D299G had an additive effect on AMD risk $(\mathrm{OR}=4.13, \mathrm{p}=0.002)$ with allelic variants of $A P O E$ and ATP binding cassette transporter-1 $(A B C A 1)$, which are involved in cholesterol efflux (Zareparsi et al. 2005b). However, the effect of TLR4, APOE and ABCA1 variants on AMD susceptibility was in contrast to that seen in atherosclerosis. But TLR4 polymorphisms have not been explored extensively across different world AMD populations compared to other candidate genes.

\section{Genetic Studies on AMD in India}

To the best of our knowledge, there are very few studies on AMD from India. There are some epidemiological studies on large cohorts (Nirmalan et al. 2004, Krisnaiah et al. 2005) and only a single study on the underlying genetic mechanisms AMD in the Indian subcontinent (Kaur et al. 2006). Our group was the first to initiate genetic association studies in AMD in India. Initially we looked into the association of SNPs in CFH, APOE and TLR4 in well characterized AMD patients and unaffected normal controls based on the AREDS criteria. Nearly $75 \%$ of the patients had late stage AMD with features like scar, choroidal neovascular membrane (CNVM) and geographic atrophy. There was a good inter-observer agreement in assignment of AMD status (Kappa value, $\mathrm{k}=0.91 \pm 0.06)$. Significant association was noted with age $(p=0.003)$ gender $(p=0.001)$ and diabetes $(p=0.001)$ to AMD susceptibility (Kaur et al. 2006).

The Y402H SNP $(C F H)$ was found to be significantly associated amongst AMD cases $\left(\mathrm{p}=1.19 \times 10^{-7}\right)$. Individuals with the risk genotype "CC" had a significantly higher risk $(\mathrm{p}<0.0001)$ of AMD than those carrying a single copy of the 
risk allele "TC" similar to other studies on different populations (Table 1). The data was consistent even after adjusting for age, gender and diabetes. We also observed that haplotypes generated with intragenic SNPs indicated similarity to the Caucasian populations. The "risk" and the "protective" haplotypes in the present data set were similar to those observed among the Caucasian populations in the west (Kaur et al. 2006).

With respect to $A P O E$, the $\varepsilon 2$ allele was slightly higher in the cases, while the $\varepsilon 4$ allele was higher in controls. But there were no differences in the genotype frequencies among patients and controls $(\mathrm{p}=0.76)$. The carriers of $\varepsilon 4$ allele had a reduced risk $(\mathrm{p}=0.03)$ of AMD $(\mathrm{OR}=0.42,95 \% \mathrm{CI}, 0.19-0.91)$. Interestingly, we did not observe any association of TLR4 with AMD (Kaur et al. 2006). But as indicated earlier, a much larger sample size would have been required to demonstrate an association of the TLR4 SNPs with AMD (Zareparsi et al. 2005b). Our data indicated a universal involvement of the $\mathrm{Y} 402 \mathrm{H}$ SNP in AMD that could be used for predictive testing (Kaur et al. 2006).

\section{Mechanisms of AMD Development}

Several pathogenic mechanisms have been proposed to understand the complex etiologies of AMD development including RPE cell death, oxidative damage of cellular components, mitochondrial dysfunction and accumulation of toxic components such as lipofuscin and advanced end glycation products (Haddad et al. 2006). It was thus proposed that variations in genes involved in inflammation, oxidative stress and cholesterol metabolism play significant role in the pathogenesis of AMD.

\section{Proteomic Analysis in AMD Patients}

Early AMD is characterized by the appearance of lipoproteinaceous deposits or drusens between RPE and choroids and associated with changes in RPE pigmentation. Proteome study of drusens demonstrated the elevated levels of oxidatively modified proteins like $\omega$-carboxyethyl pyrrole (CEP) adducts in the drusen, Bruch's membrane and plasma of AMD patients (Gu et al. 2003). These adducts are generated from oxidation of PUFAs particularly docasohexanoic acid (DHA) present in photoreceptor outer segments and have been shown to induce choroidal neovascualrization (CNV) in retinal tissues. In vitro treatment of human RPE cells with $\mathrm{CEP}$ dipeptide or CEP-HSA did not induce increased VEGF secretion suggesting that anti-CEP therapeutic modalities might be of value in limiting CNV in AMD (Ebrahem et al. 2006). CNV in retinal tissues can also be stimulated by the complement components (C3a and C5a) present in the drusen. It was shown that genetic ablation of receptors for $\mathrm{C} 3 \mathrm{a}$ or $\mathrm{C} 5 \mathrm{a}$ reduces VEGF expression, leukocyte recruitment and CNV formation after laser injury. These experiments suggested that antibody-mediated neutralization of C3a or C5a or pharmacological blockade of their receptor could be the possible therapeutic modalities for AMD (Nozaki et al. 2006).

\section{CONCLUSIONS}

Genetic association studies have led to the implication of several candidate genes in AMD in the last few years. These association studies have been meaningful as they have been widely replicated across multiple populations with varied ethnic backgrounds in clinically well characterized cohorts (Todd 2006). Moreover, the effect sizes of these variants, particularly the $C F H(\mathrm{Y} 402 \mathrm{H})$, LOC387715 (A69S) and HTRA1 have been substantially large that permitted a proper association amidst varied sample sizes in different studies (Table 1). In future, more such studies are required across wider geographical regions to identify candidates that contribute to the AMD pathogenesis. Genetic typing of AMD patients would also permit clinicians to develop correlations with genotypes for estimating disease risk and progression. Identification of susceptible gene variant(s) would allow early intervention in subjects 'at-risk' of developing AMD for a better prognosis. While the underlying biological functions of these candidate genes and their interactions are yet to be characterized, large multicentre studies with these variants should be undertaken with respect to the treatment modalities in order to understand the therapeutic mechanisms in subjects carrying the risk genotype(s).

\section{ACKNOWLEDGEMENTS}

The study was supported in part by a grant from the Department of Biotechnology (BT/ 
PR4774/Med/12/181/2004), Government of India, to SC.

\section{REFERENCES}

Age related Eye Disease Study research Group 2000. Risk factors associated with age-related macular degeneration. A case-control study in the Age-related Eye Disease Study; Age-related Eye Disease Study Report Number 3. Ophthalmology, 107: 22242232.

Age related Eye Disease Study research Group 2005. Risk factors for the incidence of advanced AgeRelated macular degeneration in the Age-Related Eye Disease Study (AREDS) AREDS Report No. 19. Ophthalmology, 11: 532-539.

Akimoto A, Akimoto M, Kuroiwa S, Kikuchi T, Yoshimura N 2001. Lack of association of mutations of the bestrophin gene with age-related macular degeneration in non-familial Japanese patients. Graefes Arch Clin Exp Ophthalmol, 239: 66-68.

Allikmets R, Seddon JM, Bernstein PS, Hutchinson A, Atkinson A et al. 1999. Evaluation of the Best disease gene in patients with age-related macular degeneration and other maculopathies. Hum Genet, 104: 449-453.

Allikmets R, Shroyer NF, Singh N, Seddon JM, Lewis RA et al. 1997. Mutation of the Stargardt disease gene (ABCR) in age-related macular degeneration. Science, 277: 1805-1807.

Ayyagari R, Zhang K, Hutchinson A, Yu Z, Swaroop A et al. 2001. Evaluation of the ELOVL4 gene in patients with age-related macular degeneration. Ophthalmic Genet, 22: 233-239.

Baird PN, Guida E, Chu DT, Vu HT, Guymer RH 2004. The epsilon2 and epsilon4 alleles of the apolipoprotein gene are associated with age-related macular degeneration. Invest Ophthalmol Vis Sci, 45: 1311-1315.

Baird PN, Islam FM, Richardson AJ, Cain M, Hunt N et al. 2006. Analysis of the $\mathrm{Y} 402 \mathrm{H}$ variant of the complement factor-H gene in age-related macular degeneration. Invest Ophthalmol Vis Sci, 47: 41944198 .

Balasubramanian D 2002. Molecular and cellular approaches to understand and treat some diseases of the eye. Curr Sci, 82: 948-957.

Blander JM and Medzhitov R 2004. Regulation of phagosome maturation by signals from toll-like receptors. Science, 304: 1014-1018.

Bressler NM 2002. Early detection and treatment of neovascular age-related macular degeneration. $J$ Am Board Fam Pract, 15: 142-152.

Cameron DJ, Yang Z, Gibbs D, Chen H, Kaminoh Y et al. 2007. HTRA1 variant confers similar risks to geographic atrophy and neovascular age-related macular degeneration. Cell Cycle, 6: 1122-1125.

Castrillo A, Joseph SB, Vaidya SA, Haberland M, Fogelman AM et al. 2003. Crosstalk between LXR and toll-like receptor signaling mediates bacterial and viral antagonism of cholesterol metabolism. Mol Cell, 12: 805-816.

Clark SJ, Higman VA, Mulloy B, Perkins SJ, Lea SM et al. 2006. His-384 allotypic variant of factor $\mathrm{H}$ associated with age-related macular degeneration has different heparin binding properties from the nondisease-associated form. J Biol Chem, 281: 2471324720.

Conley YP, Jakobsdottir J, Mah T, Weeks DE, Klein R et al. 2006. CFH, ELOVL4, PLEKHA1 and LOC387715 genes and susceptibility to age-related maculopathy: AREDS and CHS cohorts and meta analyses. Hum Mol Genet, 15: 3206-3218.

Cook DN, Pisetsky DS, Schwartz DA 2004. Toll-like receptors in the pathogenesis of human disease. Nat Immunol, 5: 975-979.

Dandona L, Dandona R, Srinivas M, Giridhar P, Vilas K et al. 2001. Blindness in the Indian State of Andhra Pradesh. Invest Ophthalmol Vis Sci, 42: 908-916.

De La Paz MA, Pericak-Vance MA, Lennon F, Haines JL, Seddon JM 1997. Exclusion of TIMP3 as a candidate locus in age-related macular degeneration. Invest Ophthalmol Vis Sci, 38: 1060-1065.

DeWan A, Liu M, Hartman S, Zhang S, Liu DTL et al. 2006. HTRA1 promoter polymorphism in wet agerelated macular degeneration. Science, 314: 989992.

Ebrahem Q, Renganathan K, Sears J, Vasanji A, Gu X et al. 2006. Carboxyethylpyrrole oxidative protein modifications stimulate neovascularization: Implications for age-related macular degeneration. Proc Natl Acad Sci USA, 103: 13480-13484.

Edwards AO, Ritter R III, Abel KJ, Manning A, Panhuysen $\mathrm{C}$ et al. 2005. Complement factor $\mathrm{H}$ polymorphism and age-related macular degeneration. Science, 308: 421-424.

Fisher SA, Rivera A, Fritsche LG, Babadjanova G, Petrov $S$ et al. 2006. Assessment of the contribution of CFH and chromosome 10q26 AMD susceptibility loci in a Russian population isolate. Br J Ophthalmol, 91: $576-578$

Friedman E 2000. The role of the atherosclerotic process in the pathogenesis of age-related macular degeneration. Am J Ophthalmol, 130: 658-663.

Gold B, Merriam JE, Zernanat J, Hancox LS, Taiber AJ et al. 2006. Variation in factor B (BF) and complement component 2 (C2) genes is associated with age-related macular degeneration. Nat Genet, 38: 458-462.

Gotoh N, Yamada R, Hiratani H, Renault V, Kuroiwa S et al. 2006. No association between complement factor $\mathrm{H}$ gene polymorphism and exudative agerelated macular degeneration in Japanese. Hum Genet, 120: 139-143.

Gu X, Meer SG, Miyagi M, Rayborn ME, Hollyfield JG et al. 2003. Carboxyethylpyrrole protein adducts and autoantibodies, biomarkers for age-related macular degeneration. J Biol Chem, 278: 42027-42035.

Haddad S, Chen AC, Santangelo SL, Seddon JM 2006. The Genetics of Age-Related Macular Degeneration: A Review of Progress to Date. Surv Ophthalmol, 51: $316-363$.

Hageman GS, Anderson DH, Johnson LV, Hancox LS, Taiber AJ et al. 2005. A common haplotype in the complement regulatory gene factor $\mathrm{H}(\mathrm{HF} 1 / \mathrm{CFH})$ predisposes individuals to age-related macular degeneration. Proc Natl Acad Sci, USA, 102: 72277232 .

Haines JL, Hauser MA, Schmidt S, Scott WK, Olson LM 
et al. 2005. Complement factor $\mathrm{H}$ variant increases the risk of age-related macular degeneration. Science, 308: 419-421.

Haines JL, Schnetz-Boutaud N, Schmidt S, Scott WK, Agarwal A et al. 2006. Functional candidate genes in age-related macular degeneration: Significant association with VEGF, VLDLR and LRP6. Invest Ophthalmol Vis Sci, 47: 329-335.

Jakobsdottir J, Conley YP, Weeks DE, Mah TS, Ferrell RE et al. 2005. Susceptibility genes for age-related maculopathy on chromosome 10q26. Am J Hum Genet, 77: 389-407.

Johnson PT, Betts KE, Radeke MJ, Hageman GS, Anderson GH et al. 2006. Individuals homozygous for the age-related macular degeneration riskconferring variant of complement factor $\mathrm{H}$ have elevated levels of CRP in the choroids. Proc Natl Acad Sci USA, 103: 17456-17461.

Kaur K, Hussain A, Hussain N, Das T, Pathangay A et al. 2006. Analysis of CFH, TLR4 and APOE polymorphism in India suggests the Tyr402His variant of $\mathrm{CFH}$ to be a global marker for age-related macular degeneration. Invest Ophthalmol Vis Sci, 47: 3729-3735.

Kiechl S, Lorenz E, Reindl M, Wiedermann CJ, Oberhollenzer $\mathrm{F}$ et al. 2002. Toll-like receptor 4 polymorphisms and atherogenesis. $N$ Engl J Med, 347: 185-192.

Kindzelskii AL, Elner VM, Elner SG, Yang D, Hughes BA et al. 2004. Toll-Like Receptor 4 (TLR4) of Retinal Pigment Epithelial Cells Participates in Transmembrane Signaling in Response to Photoreceptor Outer Segments. J Gen Physiol, 124: 139-149.

Klaver CCW, Wolf RCW, Assink JJM, van DuJin CM, Hofman A et al. 1998a. Genetic risk of age-related maculopathy. Population-Based Familial Aggregation Study. Arch Ophthalmol, 116: 1646-1651.

Klaver CC, Kliffen M, van Duijn CM, Hofman A, Cruts $\mathrm{M}$ et al. 1998b. Genetic association of apolipoprotein $\mathrm{E}$ with age-related macular degeneration. Am J Hum Genet, 63: 200-206. Erratum in: Am J Hum Genet, 63: 1252.

Klein ML, Schultz DW, Edwards A, Matise TC, Rust K et al. 1998. Age-related macular degeneration: clinical features in a large family and linkage to chromosome 1q. Arch Ophthalmol, 116: 1082-1088.

Klein R, Klein BE, Linton KL 1992. Prevalence of agerelated maculopathy. The Beaver Dam Eye Study. Ophthalmology, 99: 933-943.

Klein R, Klein BE, Franke T 1993. The relationship of cardiovascular disease and its risk factors to agerelated maculopathy: The Beaver Dam Eye study. Ophthalmology, 100: 406-414.

Klein R, Peto T, Bird A, Vannewkirk MR 2004. The epidemiology of age related macular degeneration. Am J Ophthalmol, 1376: 486-495.

Krishnaiah S, Das TP, Nirmalan PK, Nutheti R, Shamanna BR et al. 2005. Risk factors for age-related macular degeneration: Findings from Andhra Pradesh Eye Disease Study in south India. Invest Ophthalmol Vis Sci, 6: 4442-4449.

Lokki ML, Koskimies SA 1991. Allelic differences in hemolytic activity and protein concentration of $\mathrm{BF}$ molecules are found in association with particular
HLA haplotypes. Immunogenetics, 34: 242-246.

Magnusson KP, Duan S, Sigurdsson H, Petursson H, Yang $\mathrm{Z}$ et al. 2006. CFH Y402H confers similar risk of soft drusen and both forms of advanced AMD. PLoS Medicine, 3: 1-5.

Majewski J, Schultz DW, Weleber RG, Schain MB, Edwards AO et al. 2003. Age-related macular degeneration-a genome scan in extended families. Am J Hum Genet, 73: 540-550.

Mitchell P, Smith W, Attebo K, Wang JJ 1995. Prevalence of age-related maculopathy in Australia. The Blue Mountains Eye Study. Ophthalmology, 102: 14501460.

Nirmalan PK, Katz J, Robin AL, Tielsch JM, Namperumalsamy $P$ et al. 2004. Prevalence of vitreoretinal disorders in a rural population of Southern India: The Aravind Comprehensive Eye Survey. Arch Ophthalmol, 122: 581-586.

Nozaki M, Raisler BJ, Sakurai E, Sarma JV, Barnum SR et al. 2006. Drusen complement components C3a and C5a promote choroidal neovascularization. Proc Natl Acad Sci, USA, 103: 2328-2333.

Okamoto H, Umeda S, Obazawa M, Minami M, Noda T et al. 2006. Complement factor $\mathrm{H}$ polymorphisms in Japanese population with age-related macular degeneration. Mol Vis, 12: 156-158.

Rivera A, Fisher SA, Fritsche LG, Keilhauer CN, Lichtner P et al. 2005. Hypothetical LOC387715 is a second major susceptibility gene for age related macular degeneration contributing independently from complement factor $\mathrm{H}$ to disease risk. $\mathrm{Hum} \mathrm{Mol}$ Genet, 14: 3227-3236.

Ross RJ, Bojanowski CM, Wang JJ, Chew EW, Rochtchina E et al. 2007. The LOC387715 and age related macular degeneration: Replication in three casecontrol samples. Invest Ophthalmol Vis Sci, 48: 1128-1132.

Schmidt S, Klaver C, Saunders A, Postel E, De La Paz M et al. 2002. A pooled case-control study of the apolipoprotein E (APOE) gene in age-related maculopathy. Ophthalmic Genet, 23: 209-223.

Schmidt S, Saunders AM, De La Paz MA, Postel EA, Heinis RM et al. 2000. Association of the Apolipoprotein E gene with the age-related macular degeneration: Possible effect modification by family history, age, and gender. Mol Vis, 6: 287-293.

Schmidt S, Scott WK, Postel EA, Agarwal A, Hauser ER et al. 2004. Ordered subset linkage analysis supports a susceptibility locus for age-related macular degeneration on chromosome 16p12. BMC Genet, 5: 18 .

Schmidt S, Hauser MA, Scott WK, Postel EA, Aggarwal A et al. 2006. Cigarette smoking strongly modifies the association of LOC387715 and age-related macular degeneration. Am J Hum Genet, 78: 852864.

Seddon JM, Ajani UA, Mitchell BD 1997. Familial aggregation of age-related maculopathy. Am J Ophthalmol, 123: 199-206.

Seddon JM, Ajani UA, Sperduto RD, Hiller R, Blair N et al. 1994. Dietary carotenoids, vitamins A, C, and $\mathrm{E}$, and advanced age-related macular degeneration. Eye Disease Case-Control Study Group. JAMA, 272: 1413-1420. Erratum in: JAMA 1995; 273: 622

Seddon JM, Cote J, Page WF, Aggen SH, Neale MC 2005. 
The US twin study of age related macular degeneration: Relative roles of genetic and environmental influences. Arch Ophthalmol, 123: 321-327.

Seddon JM, Santangelo SL, Book K, Chong S, Cote J 2003. A genome-wide scan for age-related macular degeneration provides evidence for linkage to several chromosomal regions. Am J Hum Genet, 73: 780790.

Seddon JA, Francis PJ, George S, Schultz DW, Rosner B et al. 2007. Association of $\mathrm{CFH} \mathrm{Y} 402 \mathrm{H}$ and LOC387715 A69S with progression of age-related macular degeneration. JAMA, 297: 1793-1800.

Seitsonen S, Lemmela S, Holopainen J, Tommila P, Ranta $\mathrm{P}$ et al. 2006. Analysis of variants in the complement factor $\mathrm{H}$, the elongation of very long chain fatty acids-like 4 and the hemicentin 1 genes of age-related macular degeneration in the Finnish population. Mol Vis, 12: 796-801.

Sepp T, Khan JC, Thurlby DA, Shahid H, Clayton DG et al. 2006. Complement Factor $\mathrm{H}$ variant $\mathrm{Y} 402 \mathrm{H}$ is a major risk determinant for geographic atrophy and choroidal neovascularization in smokers and nonsmokers. Invest Ophthalmol Vis Sci, 47: 536540 .

Shastry BS, Trese MT 1999. Evaluation of the peripherin/ RDS gene as a candidate gene in families with agerelated macular degeneration. Ophthalmologica, 213: $165-170$.

Simonelli F, Frisso G, Testa F, di Fiore R, Vitale DF et al. 2006. Polymorphsim p.402Y $>\mathrm{H}$ in the complement factor $\mathrm{H}$ protein is a risk factor for age-related macular degeneration in an Italian population. $\mathrm{Br} \mathrm{J}$ Ophthalmol, 90: 1142-1145.

Souied EH, Leveziel N, Richard F, Dragon-Durey MA, Coscas G et al. 2005. Y402H Complement factor $\mathrm{H}$ polymorphism associated with exudative agerelated macular degeneration in the French population. Mol Vis, 11: 1135-1140.

Stone EM, Lotery AJ, Munier FL, Heon E, Piguet B et al. 1999. A single EFEMP1 mutation associated with both Malattia Leventinese and Doyne honeycomb retinal dystrophy. Nat Genet, 22: 199-202.

Tanimoto S, Tamura H, Ue T, Yamane K, Maruyama H et al. 2006b. A polymorphism of LOC387715 gene is associated with age-related macular degeneration in the Japanese population. Neurosci Lett, 414: 7174.
The Eye Disease Case - Control Study Group 1992. Risk factors for neovascular age-related macular degeneration. Arch Ophthalmol, 110: 1701-1708.

Todd JA 2006. Statistical false positive or true disease pathway? Nat Genet, 38: 731-733.

Tomany SC, Wang JJ, Van Leeuwen R, Klein R, Mitchell $P$ et al. 2004a. Risk factors for incident age-related macular degeneration: Pooled findings from three continents. Ophthalmology, 111: 1280-1287.

Tomany SC, Cruickshanks KJ, Klein R, Klein BE, Knudtson MD 2004b. Sunlight and the 10-year incidence of age-related maculopathy: the Beaver Dam Eye Study. Arch Ophthalmol, 122: 750-757. Erratum in: Arch Ophthalmol, 2005a, 123: 362.

Weeks DE, Conley YP, Mah TS, Paul TO, Morse L et al. 2000. A full genome scan for age-related maculopathy. Hum Mol Genet, 9: 1329-1349.

Weeks DE, Conley YP, Tsai HJ, Mah TS, Schmidt S et al. 2004a. Age-related maculopathy: a genome-wide scan with continued evidence of susceptibility loci within the 1q31, 10q26, and $17 \mathrm{q} 25$ regions. Am J Hum Genet, 75: 174-189.

World Health Organization 2004. Fact sheet no. 282. Magnitude and causes of visual impairment. http:// www.who.int/mediacentre/factsheets/fs $282 /$

Yang Z, Camp NJ, Sun H, Tong Z, Gibbs D et al. 2006. A variant of the HTRA1 gene increases susceptibility to age-related macular degeneration. Science, 314: 992-993.

Yoshida T, DeWan A, Zhang H, Sakamoto R, Okamoto $\mathrm{H}$ et al. 2007. HTRA1 promoter polymorphism predisposes Japanese to age-related macular degeneration. Mol Vis, 13: 545-548.

Zareparsi S, Branham KE, Li M, Shah S, Klein RJ et al. 2005a. Strong association of the $\mathrm{Y} 402 \mathrm{H}$ variant in complement factor $\mathrm{H}$ at $1 \mathrm{q} 32$ with susceptibility to age-related macular degeneration. Am J Hum Genet, 77: $149-153$.

Zareparsi S, Buraczynska M, Branham KE, Shah S, Eng D et al. 2005b. Toll-like receptor 4 variant D299G is associated with susceptibility to age-related macular degeneration. Hum Mol Genet, 14: 14491455.

Zareparsi S, Reddick AC, Branham KE, Moore KB, Jessup $\mathrm{L}$ et al. 2004. Association of apolipoprotein E alleles with susceptibility to age-related macular degeneration in a large cohort from a single center. Invest Ophthalmol Vis Sci, 45: 1306-1310. 